\title{
Follow up of fetal outcome in cases of maternal phenylketonuria in Northern Ireland
}

\author{
A C Magee, K Ryan, A Moore, E R Trimble
}

Arch Dis Child Fetal Neonatal Ed 2002;87:F141-F143

Background: Maternal phenylketonuria (PKU) can result in multiple congenital anomalies. In Northern Ireland, the prevalence of PKU is relatively high at 1 in 4000 .

Objective: To assess the outcome of 39 pregnancies in 20 mothers.

Results: Dietary control was established before conception in 17 pregnancies (44\%). Five mothers with hyperphenylalaninaemia had 11 pregnancies. There were no congenital anomalies in this group, and all appear to be developing normally. Fifteen women with classical PKU had 28 pregnancies. One pregnancy ended in a first trimester miscarriage. Twelve out of $27(44 \%)$ completed pregnancies produced babies with a congenital anomaly and/or developmental delay.

Conclusions: Most problems occurred when dietary control was not established until after the 2 nd trimester. As the cohort of young women with treated PKU is growing steadily, maternal PKU is going to become an even greater cause for concern.

$\mathrm{P}$ henylketonuria (PKU) was first described by Asbjorn Folling in $1934 .^{1}$ Treatment by dietary restriction of phenylalanine was introduced by Horst Bickel in $1953 .^{2}$ Since then, the clinical challenge has become the management of pregnancy in the rapidly growing population of young women of childbearing age who have been treated for PKU from the neonatal period. Phenylalanine is teratogenic to the fetus, ${ }^{3}$ and there is a positive transplacental gradient for phenylalanine. ${ }^{4}$ It is now recognised that best practice is for the woman to have a very restricted protein diet and establish phenylalanine levels of $<250 \mu \mathrm{mol} / \mathrm{l}$ for at least two months before discontinuing reliable contraception. ${ }^{56}$ She should maintain this level of control throughout the pregnancy, with accurate measurement of phenylalanine levels at least once a week. As Northern Ireland has a high prevalence of PKU-1 in $4000^{7}$ compared with the average of 1 in 10000 in other white populations, ${ }^{8}$ - the impact of maternal PKU is large. We therefore assessed the current status of maternal PKU in Northern Ireland (updating the previous report which examined pregnancy outcome up to $1993^{\circ}$ ) and looked at the implications for future care of this group of patients.

\section{METHODS}

We reviewed all known pregnancies in women with hyperphenylalaninaemia (HPA) and PKU in Northern Ireland up to the end of December 2000. Maternal intelligence quotient (IQ) was determined from patient records. Dietary control was classified as achievement of phenylalanine levels of $<250$ $\mu \mathrm{mol} / \mathrm{l}$ before conception, during the first trimester, second trimester, third trimester, or not at all during the pregnancy. Pregnancy outcome was recorded as gestation, birth weight, head circumference, and the presence or absence of any congenital anomalies. Where appropriate, the IQ of the offspring was noted. Until recently, the Department of Health PKU register was active, and required the child's IQ to be formally assessed (WISC) at age 8 years. Some younger children were assessed by the Griffiths, Stanford Binet, or Sheridan methods if there were concerns about development. In others, school performance was taken as an indicator of ability.

\section{RESULTS}

Five women with HPA had 11 pregnancies. All recorded phenylalanine levels were below $500 \mu \mathrm{mol} / \mathrm{l}$. Maternal IQ was known in three mothers, who scored 96, 101, and 104. There were no congenital anomalies in this group. One child has classical PKU, and another has mild developmental delay.

Fifteen women with classical PKU had 28 pregnancies, one ending in a first trimester miscarriage. Maternal IQ was recorded for nine women and ranged from 73 to 102 . No increase in prematurity or intrauterine growth retardation was noted. The outcome with regard to congenital anomaly is known in all 27 completed pregnancies. There is no information on development in four children. In two pregnancies, the outcome was stillbirth and anencephaly. Therefore developmental information is available for 21 of the cohort.

In seven women (11 pregnancies) dietary control was established before conception and continued throughout pregnancy. In this group, one child was stillborn and one had a congenital heart defect. No post mortem anomaly was found in the stillborn baby. One child has a borderline IQ.

In five women (seven pregnancies) dietary control was established in the first trimester of pregnancy. Three of these offspring have a congenital anomaly (anencephaly, unilateral talipes, and pyloric stenosis), but there is no evidence of mental retardation in the latter two.

Two women had their diet controlled in the second trimester; one infant had multiple anomalies and severe developmental delay, but chromosome analysis showed a deletion of $4 \mathrm{p}$. It is not possible to assess which, if any, of this infant's problems can be attributed to his mother's PKU. She presented at 20 weeks gestation with no dietary control and a phenylalanine level of $652 \mu \mathrm{mol} / \mathrm{l}$.

Another two women did not achieve control of their diet until the 3rd trimester; one child has marked microcephaly but is at mainstream school with normal development.

Three women (five pregnancies) never established dietary control. Four offspring have mild to moderate mental retardation, two are microcephalic, and one has congenital heart defects, gastroschisis, and subglottic stenosis. In the remaining pregnancy in this group, dietary control was attempted, but recorded levels ranged from 557 to $879 \mu \mathrm{mol} / \mathrm{l}$.

In summary, 9/27(33\%) of the offspring of mothers with classical PKU had a congenital anomaly. Where information is

Abbreviations: PKU, phenylketonuria; HPA, hyperphenylalaninaemia; $I Q$, intelligence quotient 
Table 1 Pregnancy outcome and dietary control in maternal hyperphenylalaninaemia (HPA) and phenylketonuria (PKU)

\begin{tabular}{|c|c|c|c|c|c|c|c|}
\hline \multirow[b]{2}{*}{ Case } & \multirow[b]{2}{*}{ Congenital anomaly } & \multirow[b]{2}{*}{ IQ } & \multicolumn{5}{|c|}{ Diet established } \\
\hline & & & $\begin{array}{l}\text { Before } \\
\text { conception }\end{array}$ & $\begin{array}{l}1 \text { st } \\
\text { trimester }\end{array}$ & $\begin{array}{l}\text { 2nd } \\
\text { trimester }\end{array}$ & $\begin{array}{l}3 r d \\
\text { trimester }\end{array}$ & None \\
\hline \multicolumn{8}{|l|}{ HPA } \\
\hline 1 & PKU & $\mathrm{N}$ & + & & & & \\
\hline 2 & - & $\mathrm{N}$ & + & & & & \\
\hline 3 & - & $\mathrm{N}$ & + & & & & \\
\hline 4 & - & Below average, age 3, Stanford Binet & + & & & & \\
\hline 5 & & $\mathrm{~N}$ & + & & & & \\
\hline 6 & - & $\mathrm{N}$ & + & & & & \\
\hline 7 & - & IQ 112 , age 8 WISC & & + & & & \\
\hline 8 & - & $\mathrm{N}$ & & + & & & \\
\hline 9 & - & $12-14 \mathrm{~m}$, age $11 \mathrm{~m}$, Griffith & & + & & & \\
\hline 10 & - & $\mathrm{N}$ & & & & & + \\
\hline 11 & - & $\mathrm{N}$ & & & & & + \\
\hline \multicolumn{8}{|l|}{ PKU } \\
\hline 12 & IUD, stillborn, normal & N/A & + & & & & \\
\hline 13 & VSD & $\mathrm{N}$ & + & & & & \\
\hline 14 & - & $?$ & + & & & & \\
\hline 15 & - & $?$ & + & & & & \\
\hline 16 & - & Normal $18 \mathrm{~m}$, Sheridan & + & & & & \\
\hline 17 & - & $\mathrm{N}$ & + & & & & \\
\hline 18 & - & N/A & + & & & & \\
\hline 19 & - & IQ 85, age 8 WISC & + & & & & \\
\hline 20 & - & $\mathrm{N}$ & + & & & & \\
\hline 21 & - & IQ 111 , age 8 WISC & + & & & & \\
\hline 22 & - & $\mathrm{N}$ & + & & & & \\
\hline 23 & - & $\mathrm{N}$ & & + & & & \\
\hline 24 & Anencephaly & N/A & & + & & & \\
\hline 25 & - & IQ 127 , age 8 WISC & & + & & & \\
\hline 26 & - & $\mathrm{N}$ & & + & & & \\
\hline 27 & Unilateral talipes with shortening & $\mathrm{N}$ & & + & & & \\
\hline 28 & - & $\mathrm{N}$ & & + & & & \\
\hline 29 & Pyloric stenosis & $\mathrm{N}$ & & + & & & \\
\hline 30 & - & $?$ & & & + & & \\
\hline 31 & $\begin{array}{l}\text { Deletion } 4 p \text { multiple congenital } \\
\text { anomalies }\end{array}$ & Developmental delay & & & + & & \\
\hline 32 & - & $?$ & & & & + & \\
\hline 33 & Microcephaly & $\mathrm{N}$ & & & & + & \\
\hline 34 & - & $\mathrm{N}$ & & & & & + \\
\hline 35 & - & IQ 82 age 8 WISC & & & & & + \\
\hline 36 & Microcephaly ptosis & Developmental delay & & & & & + \\
\hline 37 & Microcephaly & Developmental delay & & & & & + \\
\hline 38 & $\begin{array}{l}\text { PDA, VSD, gastroschisis, } \\
\text { subglottic stenosis }\end{array}$ & Developmental delay & & & & & + \\
\hline 39 & 1st trimester miscarriage & N/A & + & & & & \\
\hline
\end{tabular}

available about developmental outcome, 6/21 (29\%) have some degree of delay. In all, 12 children have congenital anomaly and/or developmental delay. If we consider this as either a proportion of the 21 for which full information is available, or a proportion of all 27 pregnancies, the incidence of congenital anomaly and/or developmental delay is $44-57 \%$ (table 1 ).

In 17 of the 39 pregnancies $(44 \%)$, dietary control was established before conception.

\section{DISCUSSION}

Our results indicate an unacceptably high incidence of anomaly associated with maternal PKU. The few women with HPA and phenylalanine levels $<500 \mu \mathrm{mol} / \mathrm{l}$ do not present a major problem, but it must be noted that all needed a protein restricted diet before and during pregnancy. When the effects of maternal PKU were first recognised, reports indicated a risk of about $90 \%$ for mental retardation, $75 \%$ for microcephaly, $40-50 \%$ for intrauterine growth retardation, and $12-25 \%$ for congenital anomalies. ${ }^{11}{ }^{11}$ It has even been suggested that surrogacy would provide a "safe haven" for the offspring of mothers with PKU. ${ }^{12}$

It is now evident that the best results for mothers with PKU are obtained when phenylalanine levels are controlled before and during pregnancy. ${ }^{13}{ }^{14}$ However, ideal phenylalanine levels are not the whole answer. Tyrosine supplements may be necessary, and essential fatty acid intake must also be monitored. Some women find it difficult to maintain an adequate energy intake. These dietary regimens make huge demands not only on the woman but also on dietetic and medical personnel. One report has suggested that, in the space of one generation, the incidence of new cases of PKU related mental retardation could return to the former level. ${ }^{15}$ A recent report on maternal PKU, an international study covering 574 pregnancies in 382 hyperphenylalaninaemic mothers, identified an association of poor pregnancy outcome with mean maternal IQ $<83$ and low socioeconomic status. ${ }^{16}$ In that report, dietary control was established before conception in $25.8 \%$ of pregnancies ( $44 \%$ in our group). We are concerned that the nationwide follow up of these children is no longer centralised because funding for the national PKU register has ceased. Information on the outcome of maternal PKU in the United Kingdom will now depend on each clinic organising individual monitoring. The work of the national PKU register allowed detailed documentation of congenital anomalies and also developmental assessments. We found that the mothers with PKU were reasonably keen to comply with this when they felt it was helpful to the PKU population in general. Perhaps it is time to reconsider the possible benefits of national guidelines, and the required infrastructure, for monitoring pregnancy outcome in this increasing population. 
In Northern Ireland, we have details of 96 women with PKU who are of childbearing age ( $\geqslant 13$ years) and a further five women with HPA. This predicts the need for a major input of education, support, and encouragement to minimise the incidence of PKU related handicap. We believe that this is an achievable goal of preventive medicine, and that these young women deserve the multidisciplinary help they need in order to plan their pregnancies and produce healthy babies.

\section{Authors' affiliations}

A C Magee, Regional Genetics Service, Belfast City Hospital Trust, Lisburn Road, Belfast BT9 7AB, Northern Ireland, UK

K Ryan, E R Trimble, Department of Clinical Biochemistry, Royal Group of Hospitals Trust, Falls Road, Belfast BT12 6BE

A Moore, Department of Dietetics, Royal Group of Hospitals Trust

Correspondence to: Professor Trimble, Department of Clinical Biochemistry, Royal Group of Hospitals Trust, Falls Road, Belfast BT1 2 6BE, Northern Ireland, UK; e.trimble@quh.ac.uk

Accepted 29 January 2002

\section{REFERENCES}

1 Folling A. Uber ausscheidung von phenylbrenztraubensaure in den Harn als Stoffwechselanomalie in verbingdung mit imbezillitat. Hoppe-Seylers Z Physiol Chem 1934;227:169-76.
2 Bickel H, Gerrard J, Hickmans EM. Influence of phenylalanine intake on phenylketonuria Lancet 1953:2:812.

3 Dent CE. Discussion of Armstrong MD. Relation of biochemical abnormality to development of mental defect in phenylketonuria. In: Etiological factors in mental retardation: report of the 23rd Ross Pediatric Research Conference November 8-9, 1956. Columbus, OH: Ross Laboratories, 1957

4 Kerr GR, Chamove AS, Harlow HF, et al. "Fetal PKU": the effect of maternal hyperphenylalaninaemia during pregnancy in the Rhesus monkey (Macaca mulatta). Pediatrics 1968:42:27-36.

5 Smith I. Recommendations on the dietary management of phenylketonuria. Report of Medical Research Council Working Party on Phenylketonuria. Arch Dis Child 1993;68:426-7.

6 Koch R, Levy HL, Hanley WB, et al. Outcome implications of the

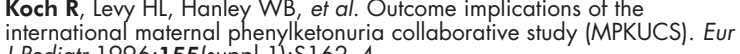

J Pediatr 1996; 155(suppl 1):S162-4.
7 Zschocke J, Mallory JP, Eiken HG, et al. Phenylketonuria and the peoples of Northern Ireland. Hum Genet 1997;100:189-94.

8 Bickel H, Bachman C, Beckers R. Neonatal mass screening for metabolic disorders. Eur J Pediatr 1981;37:133-9.

9 Whitehead H, Holmes J, Roberts R, et al. Maternal phenylketonuria 1987 to 1993, pregnancy outcome and early infant development: the Northern Ireland experience. Br J Obstet Gynaecol 1996:103:1041-4.

10 Lenke RR, Levy HL. Maternal phenylketonuria and hyperphenylalaninaemia: an international survey of the outcome of untreated and treated pregnancies. N Engl J Med 1980;303:1201-8.

11 Hanley WB, Clarke JTR, Schoonheyt W. Maternal phenylketonuria (PKU): a review. Clin Biochem 1987;20:149-56.

12 Fisch RO, Tagatz G, Stassart JP. Gestational carrier: a reproductive haven for offspring of mothers with phenylketonuria (PKU): an alternative therapy for maternal PKU. J Inher Metab Dis 1993;16:957-61.

13 Cipcic-Schmidt S, Trefz FK, Funders B, et al. German maternal phenylketonuria study. Eur J Pediatr 1996;155(suppl 1):S173-6. 4 Brenton DP, Lilburn M. Maternal phenylketonuria. A study from the United Kingdom. Eur J Pediatr 1996;155(suppl):S177-80.

15 Kirkman HN. Projections of a rebound in frequency of mental retardation from phenylketonuria. Appl Res Ment Retard 1982;3:319-21.

16 Koch R, Hanley W, Levy H, et al. Minireview. Maternal phenylketonuria: an international study. Mol Genet Metab 2000;71:233-9.

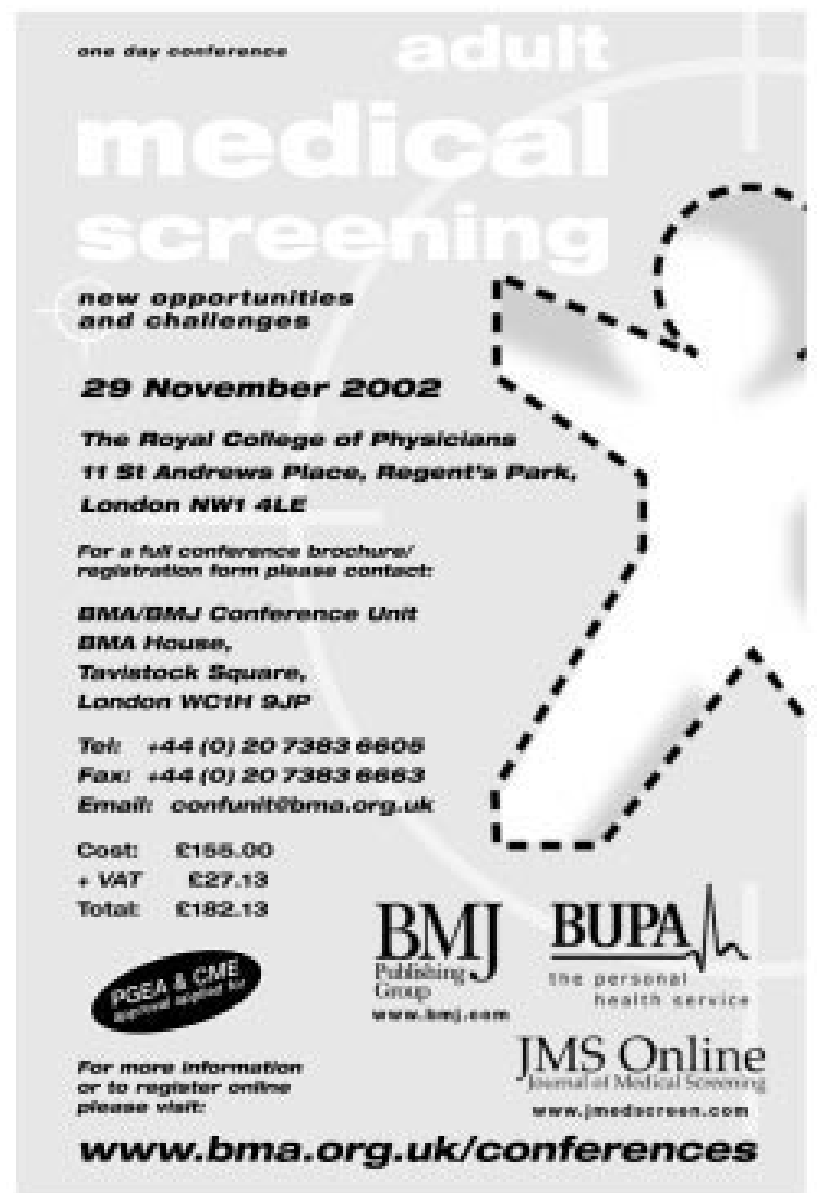

